\title{
A structural move analysis of the abstract section of ISI articles of Iranian and native scholars in the field of agricultural engineering
}

Tavakoli Gheinani, Majid

Islamic Azad University, Najafabad Branch, Iran (majidtavakoli.edu93@yahoo.com)

Tabatabaei, Omid $\unrhd$

Islamic Azad University, Najafabad Branch, Iran (tabatabaeiomid@yahoo.com)

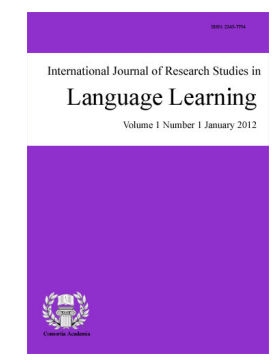

ISSN: 2243-7754 Online ISSN: 2243-7762

\section{Abstract}

This study aimed at investigating the rhetorical moves that are used in the abstract section of ISI articles in the field of agricultural engineering and figuring out the differences between Iranian and native English scholars in using the moves in their abstracts. The other goal of the study was to figure out the obligatory and optional moves of the abstracts. To this end, 120 abstracts containing 60 abstracts written by Iranian scholars and 60 abstracts written by native English scholars published in ISI journals between 2010 and 2015 in the field of agricultural engineering were selected. The results indicated that there were significant differences between Iranian and native scholars in using move 1 and move 3, while there were not significant differences between the two groups of writers in using move 2 , move 4 , and move 5. The findings of the present study may contain some implications for ESP instruction and academic writing.

Keywords: abstract; agricultural engineering; genre analysis; move analysis; research article; rhetorical move 


\section{A structural move analysis of the abstract section of ISI articles of Iranian and native scholars in the field of agricultural engineering}

\section{Introduction}

An abstract is defined as a succinct summary of a research article, thesis, review, conference proceeding or any thorough analysis of a specific subject or field, and is regularly used to help the reader quickly find out the paper's purpose (Blake \& Bly, 1993). The abstract allows the reader to understand the important parts of the study without reading the other parts. The common length of an abstract is normally from 100 to 250 words and it contains the major features and findings of the study (Van Bonn \& Swales, 2007). A good abstract is "accurate, non-evaluative, concise, coherent, and reliable" (American Psychological Association, 2001, p. 26). Abstracts always appear at the beginning of the papers and act as the entry point for all academic documents or patent applications. Even though they are short, abstract writing has a specific type and formal structure that are accepted by academic discourse communities (San \& Tan, 2012).

That is to say, this formal structure is realized as the rhetorical moves in abstract writing. The first organization of moves was done by Swales $(1981,1990)$ in the introduction section of Research Articles (RA). Swales stated that a proper introduction must have three moves. Move 1 is establishing a theory in which the writer must maintain the significance of the work, making topic generalization, and reviewing previous studies. Move 2 is establishing a niche where the writer has to identify the gap in the literature. Move 3 is occupying the niche where the writer utters the goal of the study.

Dos Santos (1996) proposed a new move pattern for abstract writing which consisted of five moves. The first move is Move 1 which is Situating the research (STR) in which the setting for the current research is discussed, followed by Move 2, Presenting the research (PTR). In Move 2, the purpose of the study, research questions or hypotheses are presented. The next move is Move 3, which is Describing the methodology (DTM). It describes the materials, subjects, variables, and procedures used in a study. This move is then followed by the findings of the study in Move 4, which is known as Summarizing the findings (STF). In this move, the writers report the main findings of the study in brief. Finally, the framework ends with Move 5, Discussing the research (DTR) where the results or findings are found. In this move recommendations, implications or applications are discussed. Santos (1996) stated that Move 1 and Move 5 are optional, while Move 2, Move 3, and Move 4 are obligatory moves. Furthermore, Hyland (2000) proposed a five-move pattern model. Hyland's model included: (a) introduction, which establishes the context of the paper and motivates the research, (b) purpose, which indicates purpose, hypothesis, and outlines the intention behind the paper, (c) method, which provides information on design, procedures, assumptions, approach, data, etc., (d) product, which states the main findings or results, the argument, or what was accomplished, and (e) conclusion, which interprets or extends results beyond the scope of the paper and draws inferences (Hashemi \& Saboori, 2013).

Iranian scholars in the field of agricultural engineering tend to publish their findings in the ISI journals. In order to reach to this goal, they need to be completely familiar with the structure of the abstract and the moves that must be used in abstract writing to write organized and comprehensive abstracts. Therefore, an attempt has been made in this study to identify what rhetorical moves are used in the abstract section of ISI articles in the field of agricultural engineering and if there is a difference between Iranian and native-English writers in following the proper move pattern in this field.

\subsection{Research questions}

The answers to the following research questions were pursued in this study: 
Q1: What rhetorical moves are used by Iranian writers in writing the abstract section of ISI articles in the field of agricultural engineering?

Q2: What rhetorical moves are used by native-English writers in writing the abstract section of ISI articles in the field of agricultural engineering?

Q3: What are obligatory and optional moves in the abstract section of ISI articles written by Iranian and native-English writers in the field of agricultural engineering?

Q4: Is there a significant difference between Iranian and native-English writers of ISI articles based on the move usage frequency in the abstract section in the field of agricultural engineering?

\subsection{Research Hypothesis}

The current study was conducted based on the following research hypothesis:

Ho: There is no significant difference between Iranian and native-English writers of ISI articles based on the move usage frequency in the abstract section.

\section{Review of the Literature}

\subsection{Genre and Genre Analysis}

A genre contains a category of communicative incidents in which its members share a series of communicative goals (Swales, 1990). According to Hyland (2008), Genre is a term for a group of texts together, representing how writers normally use language to respond to different situations. According to Richards and Schmidt (2010), a genre is a type of discourse that occurs in a particular setting, that has distinctive and recognizable patterns and norms of organization and structure, and contains particular and distinctive communicative functions.

"Genre analysis incorporates a variety of frameworks used to analyze a range of textual genres constructed, interpreted, and used by members of various disciplinary communities in academic, professional, workplace and other institutional contexts" (Bhatia, 2015, p. 1). The analyses vary from close linguistic studies of texts as products, to studies about the dynamic convolution of broad practices of professional and workplace communities (Bhatia, 2014), and added to a comprehensive perception of socio-cultural and critical practices often concentrating on processes of interpreting these textual genres in real life settings (Bhatia, 2004; Swales, 2004).

\subsection{Move and Move Analysis}

Swales and his followers tried to analyze the discourse of various disciplines and the employed Moves in them. Swales (2004, p. 29) defined move in genre analysis as "a discoursal [sic] or rhetorical unit that performs a coherent communicative function in a written or spoken discourse." According to Swales (2004, p. 20), "a Move, at one extreme, can be realized by a clause; at the other by several sentences. It is a functional not a formal unit." Ding (2007) defined move in EAP writing as a practical unit in a text, which is related to the whole task and employed to categorize the textual regularities in particular genres of writing. Moreover, move analysis is an important aspect of genre analysis that has been detected to be very insightful for genre analysis in both ESP and EAP (Bhatia, 2001). According to Swales (1990) and Bhatia (1993), a genre is a set of recognizable communicative events each with a similar purpose and a conventionalized social and schematic structure. The schematic structure can be seen in terms of a series of optional and obligatory moves (Bhatia, 2014; Swales, 1990 ) with each move contributes to the writer's overall communicative purpose. 


\subsection{Studies on Analyzing Research Articles Abstracts}

Wang (2015) studied the rhetorical variation of abstracts written by professionals and Chinese undergraduate students by investigating 60 RA abstracts in applied linguistics. Santos' (1996) five-move model was applied as the analytical framework. The results revealed that abstracts by the two groups of writers shared Move 2, 3 and 4 as conventional. However, the move pattern varied considerably among them. Relating to verb tense, in the face of the similar propensity to use the present tense in Move 1,2 and 5, there were great differences in all the five moves in terms of occurrence frequency.

In another study Maswana, Kanamaru, and Tajino (2015) analyzed the rhetorical structure of 67 engineering research articles from five sub-disciplines: structural engineering, environmental engineering, electrical engineering, chemical engineering, and computer science. Six engineering researchers participated in the study by coding texts of full-length papers into moves and steps. The findings of the study indicated that the abstract, introduction, and concluding sections and some of their moves were common among all sub-disciplines.

\subsection{Studies on Analyzing Iranian Research Articles Abstracts}

Nasseri and Nematollahi (2014) analyzed the abstracts of MA theses written by Iranian and native-English writers in applied linguistics and they concluded that in both groups only 25 percent of the writers used the last move, Discussing the research, and both groups considered it as optional. About Move 1, 50 percent of Iranian writers used it in their abstracts while other moves were considered as obligatory moves by both native and Iranian writers.

Behnam and Golpour (2014) analyzed the abstracts of the research articles written by Iranian and English writers in applied linguistics and mathematics and they found that because the method move was present in all abstracts, therefore, it is the only obligatory move in both disciplines. Behnam and Golpour (2014) also stated that describing the methodology is the important part of the abstract for both disciplines. They also revealed that Move 3 in mathematics abstracts appeared as an independent move, but 25 percent of the Move $3 \mathrm{~s}$ in linguistic abstracts were embedded in Move 3 in a packed form, hence Move 3 in mathematics abstracts was more important than in linguistics abstracts. They also revealed that Move 4 was used more often in Persian writers' abstracts than in English writers' abstracts.

Abarghooeinezhad and Simin (2015) analyzed structural move analysis of abstract in electronic engineering articles and they revealed that except Move 2, there is in no significant difference between Iranian and native-English writers in abstract writing in the field of electronic engineering. They also found that Move 2 and Move 3 are considered as obligatory moves both by Iranian and English writers based on Santos's model. They stated that only a small percentage of both Iranian and English authors put all five Moves proposed by Santos into operation, which indicates Santos model is not capable of predicting research article abstracts in engineering.

\section{Methodology}

The methodology for conducting the study consisted of the corpus of the study, instruments, and procedure.

\subsection{Corpus of the Study}

The corpus of this study consisted of 120 research article abstracts (60 Iranian ISI abstracts and 60 native-English ISI abstracts) in the field of agricultural engineering published in ISI journals by Iranian and native-English scholars between 2010 and 2015. Journals with the international reputation among the top ones with the highest IF in the discipline of agricultural engineering were selected. These journals which have been registered by ISI (recently Thompson Reuters), are leading journals in their academic societies and publications in the journals are widely cited in the agriculture field. First, a comprehensive list of journals was collected. After 
A structural move analysis of the abstract section of ISI articles of Iranian and native scholars

that, 20 journals from the list were chosen in the field of agricultural engineering.

In addition, for the Native-English category, articles were checked in terms of the nationality of their authors; therefore, all writers were asked whether English is their first language or not through e-mail and they confirmed that they are native speakers of English. At last, 60 abstracts from each category from the journals with higher impact factors were selected. To do an accurate analysis and in order to be able to use AntMover software, articles were grammatically analyzed and the ones with no grammatical deviations were used.

\subsection{Instruments}

Two types of instruments were used to perform this study, which were AntMover software and Hyland's (2000) five-move model.

AntMover software - This software is developed by Laurence Anthony in 2003. It is a text structure analyzer software, which can be easily available on the Internet. While the text file is opened, the user can choose up to four views of the file. (a) The original text without any analysis, (b) the text that has been separated into sentences, (c) the text, which contains different sentences with rhetorical labels, and (d) outline view of the rhetorical features. Regarding the move/sub-moves recognition, all the corpus abstracts will be imported into the program (Anthony, 2003).

Hyland's (2000) Five-Move Model - The reason for selecting this model is that it has been found to be the most appropriate one for the structure of the examined abstracts especially due to the helpful distinction it offered between introducing the background research area and presenting the research purpose (Suntara \& Usaha, 2013). The five moves are (1) Introduction, which establishes context of the paper and motivates the research, (2) Purpose in which the intention behind the paper is introduced, (3) Method that provides information on design, procedures, assumptions, (4) Product where main findings or results are stated, and (5) Conclusion which interprets or extends results beyond the scope of the paper. A move unit can be composed of one or more sentences or, at least, clauses.

\subsection{Procedure}

In order to collect the Iranian corpus, the researcher used some of the most prominent agricultural colleges of Iranian universities' websites, such as Shiraz University, Isfahan University of Technology, and Ferdowsi University of Mashhad. The corpus was selected from the ISI articles that are published by the researchers of these universities between 2010 and 2015. In the first step, 120 abstracts were chosen and then 60 abstracts that were published in journals with higher impact factors were selected for further analysis. The same procedure was used for the native corpus, but the articles were selected among American and Canadian universities, such as College of Agricultural and Life Sciences University of Wisconsin-Madison, The University of Tennessee Institute of Agriculture, and College of Agriculture and Bioresources University of Saskatchewan.

Moreover, after collecting the entire corpus, each abstract was saved as a *.txt file to be submitted to the AntMover for move analysis. A structural Move analysis was run by two human coders who separately coded each abstract and identified the moves. They labeled the moves according to the model proposed by Hyland's (2000) five-move model framework for abstract analysis. Then a meeting was held to label the Moves by human coders, and software outputs were compared.

Inter-Coder Reliability - To make sure about the inter-coder reliability the Kappa Statistic was used by the researcher. Inter-observer variation can be calculated in all situations in which two or more independent observers are assessing the same thing. Kappa gives a numerical rating of the degree to which this occurs (Viera \& Garrett, 2005). The calculation is based on the comparison between the differences of the "observed agreement" which states that how much agreement is actually present and the "expected agreement" which says how much agreement would be expected to be present by chance alone. The observed agreement is simply the 
Tavakoli Gheinani, M., \& Tabatabaei, O.

percentage of all lectures for which the two residents' evaluations agree, which is the sum of a $+\mathrm{d}$ divided by the total n (Viera \& Garrett, 2005). The following table shows the criteria of Kappa interpretation.

\section{Table 1}

The Kappa Interpretation

\begin{tabular}{cc}
\hline Kappa & Interpretation \\
\hline$<0$ & Poor agreement \\
$0.0-0.20$ & Slight agreement \\
$0.21-0.40$ & Fair agreement \\
$0.41-0.60$ & Moderate agreement \\
$0.61-0.80$ & Substantial agreement \\
$0.81-1.00$ & Almost perfect agreement \\
\hline Source: Viera \& Garrett $(2005)$ &
\end{tabular}

According to Table 2, the inter-rater reliability for the coders in Move 1 was found to be Kappa $=0.816(p<$ $0.001)$, the inter-rater reliability for the coders in Move 3 was Kappa $=0.769(p<0.001)$, and the inter-rater reliability for the coders in Step 5b was Kappa $=0.853(p<0.001)$. Based on these Kappa results, it was revealed that there was an almost perfect agreement between coders for Move 1 and Step 5b, while the agreement between coders in Move 3 was substantial according to Table 1. The average of Kappa for all moves and steps was 0.91 , which indicated almost perfect agreement between the coders of the study.

\section{Table 2}

The Kappa Interpretation Results

\begin{tabular}{|c|c|c|c|c|c|c|}
\hline & $\begin{array}{l}\text { Approx. } \\
\text { Sig. }\end{array}$ & $\begin{array}{l}\text { Approx. } \\
\text { T }^{\mathbf{b}}\end{array}$ & $\begin{array}{l}\text { Asymp. Std. } \\
\text { Error }^{\mathrm{a}}\end{array}$ & Value & & \\
\hline Move 1 & .000 & 8.853 & .062 & $\begin{array}{l}.816 \\
120\end{array}$ & Kappa & $\begin{array}{l}\text { Measure of Agreement } \mathrm{N} \text { of Valid } \\
\text { Cases }\end{array}$ \\
\hline Move 3 & .000 & 8.425 & .078 & $\begin{array}{l}.769 \\
120\end{array}$ & Kappa & $\begin{array}{l}\text { Measure of Agreement } \mathrm{N} \text { of Valid } \\
\text { Cases }\end{array}$ \\
\hline Step 5b & .000 & 9.446 & .145 & $\begin{array}{l}.853 \\
120 \\
\end{array}$ & Карра & $\begin{array}{l}\text { Measure of Agreement } \mathrm{N} \text { of Valid } \\
\text { Cases }\end{array}$ \\
\hline
\end{tabular}

Note. a. Not assuming the null hypothesis. b. Using the asymptotic standard error assuming the null hypothesis.

\section{Results}

To answer the first and second research questions the frequencies and percentages of the occurrence of each move and sub-move, which was used in the abstracts written by Iranian and native scholars, were calculated and the results were tabulated and displayed by figures. In order to answer the third research question, the assumption made by Santos (1996) and Pho (2008) was used. According to them, to determine an obligatory move, the occurrence of a move or sub-move must be at least $80 \%$ and moves or sub-moves, which occur below this level, must be considered optional. For answering the fourth research question, the Chi-square test was conducted to make comparisons between Iranian and native scholars in using each move and sub-move in their abstracts.

\subsection{Frequencies and Percentages of the Moves in the Corpus}

The descriptive statistics were used for calculating the moves in the corpus. By the information that was obtained by the analysis of the abstracts, it was revealed that native writers used Move 1 in their abstracts more than Iranian writers did (Iranian abstracts: 39, native abstracts: 51). Considering Move 2, all abstracts written by Iranian and native scholars contained this move. About Move 3, Iranian writers used this move in their abstracts more than native writers did (Iranian abstracts: 56, native abstracts: 43). Almost all native and Iranian scholars used Move 4 in their abstracts (Iranian abstracts: 59, native abstracts: 58). The use of Move 5 was also very high by Iranian and native writers and 59 abstracts of each group contained this move. The results of the analysis are 
illustrated in the following table and figure.

Table 3

Frequencies of the Moves in the Abstracts

\begin{tabular}{lccccc}
\hline & Move 1 & Move 2 & Move 3 & Move 4 & Move 5 \\
\hline Iranians & 39 & 60 & 56 & 59 & 59 \\
Natives & 51 & 60 & 43 & 58 & 59 \\
\hline
\end{tabular}

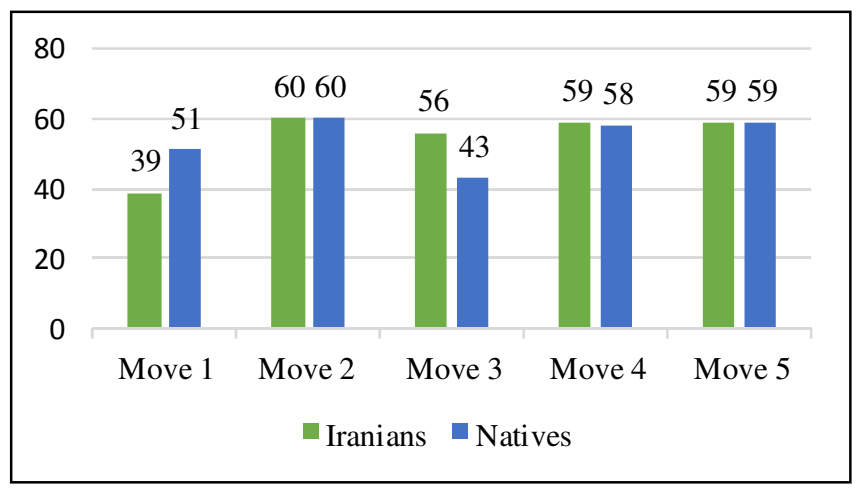

Figure 1. Frequencies of the Moves in the Abstracts

As it is shown in Table 4, 65\% of abstracts written by Iranian writers contained Move 1 while $85 \%$ of the abstracts written by native writers contained Move 1 therefore, this move was considered optional by Iranian scholars and obligatory by native scholars. Move 2 was used in all abstracts then, this move was regarded as obligatory by both Iranian and native scholars. The occurrence of move 3 was $93 \%$ in the Iranian abstracts and $72 \%$ in the native abstracts, hence this move was regarded as obligatory by Iranian scholars and optional by native scholars. Move 4 and Move 5 were considered obligatory by Iranian and native scholars because of their very high occurrences. Move 4 was used in $98 \%$ of Iranian abstracts and 97\% native abstracts while move 5 was used in $98 \%$ of both Iranian and native abstracts.

\section{Table 4}

Percentages of the Moves in the Abstracts

\begin{tabular}{lccccc}
\hline & Move 1 & Move 2 & Move 3 & Move 4 & Move 5 \\
\hline Iranians & $65 \%$ & $100 \%$ & $93 \%$ & $98 \%$ & $98 \%$ \\
Natives & $85 \%$ & $100 \%$ & $72 \%$ & $97 \%$ & $98 \%$ \\
Total & $75 \%$ & $100 \%$ & $83 \%$ & $98 \%$ & $98 \%$ \\
\hline
\end{tabular}

\subsection{Frequencies and Percentages of the Sub-Moves in the Corpus}

In the Hyland's (2000) model, Moves 1, 3, and 5 have more than one sub-moves or steps. Move 1 consists of four steps and Moves 3 and 5 contain three sub-moves. Sub-Move 1a was used in 15 abstracts written by Iranian writers, which means its occurrence was $25 \%$ in the Iranian abstracts, while this step was used in 12 abstracts written by native writers which means its occurrence was $20 \%$ in the native abstracts. The results suggested that neither Iranians nor natives regarded this step as obligatory. Sub-Move 1b was used in 29 of Iranian abstracts which means it occurred in $48 \%$ of Iranian abstracts while it was used in 48 abstracts written by native writers which means its occurrence was $80 \%$. According to the results, native scholars considered this sub-move obligatory while Iranian scholars considered it optional.

Accordingly, Regarding Sub-Move 1c, it was used in 25 Iranian abstracts which means $42 \%$ of their abstracts contained this move whereas this sub-move was used in 27 of native abstracts which means $45 \%$ of 
Tavakoli Gheinani, M., \& Tabatabaei, O.

their abstracts contained it. Due to its very low occurrences, it can be noted that both Iranian and native writers believed that this step was optional. Sub-Move 1d was used in six abstracts written by Iranian scholars which means it was used in $10 \%$ of Iranian abstracts while this move was used in 16 abstracts written by native scholars which means $27 \%$ abstracts contained this sub-move. Based on the results, this step was considered optional by both Iranian and native writers.

Additionally, Move 3 consists of three sub-moves. Sub-Move 3a was the least common step and was used only in one Iranian abstract which means this was an optional step. Sub-Move 3b was used in 53 abstracts written by Iranian writers which means it occurred in $88 \%$ of the abstracts and it was regarded as obligatory by Iranian scholars, while this sub-move was used in 35 abstracts written by native writers which means its occurrence was $58 \%$ and it was considered optional by native scholars. Sub-Move 3c was used in 49 Iranian abstracts which means its occurrence was $82 \%$ and regarded as obligatory by Iranian writers whereas this step was used in 36 native abstracts which means its occurrence was $60 \%$ and considered an optional sub-move by native writers.

Furthermore, Move 5 also contains three sub-moves. Sub-Move 5a had the highest occurrence among all the steps in the abstracts written by Iranian and native scholars. This step was used in 58 abstracts written by Iranian scholars which means $97 \%$ of the abstracts contained this sub-move whereas this step was used in 59 abstracts written by native scholars which means $98 \%$ of abstracts contained this sub-move. This sub-move was considered obligatory by both native and Iranian scholars. Sub-Move $5 \mathrm{~b}$ was used in 15 Iranian abstracts which means its occurrence was $25 \%$ while this step was used in 11 abstracts written by native scholars which means its occurrence was $18 \%$ and considered optional by both Iranian and native writers. Sub-Move 5c was used in 11 abstracts written by Iranian writers which means its occurrence was $18 \%$ while it was used in eight abstracts written by native writers which means its occurrence was $13 \%$. This step was deemed optional by Iranian and native scholars. The following tables and figure illustrate the results of the analyses.

Table 5

Frequencies of the Sub-Moves in the Corpus

\begin{tabular}{lcccccccccc}
\hline & Step 1a & Step 1b & Step 1c & Step 1d & Step 3a & Step 3b & Step 3c & Step 5a & Step 5b & Step 5c \\
\hline Iranians & 15 & 29 & 25 & 6 & 1 & 53 & 49 & 58 & 15 & 11 \\
Natives & 12 & 48 & 27 & 16 & 0 & 35 & 36 & 59 & 11 & 8 \\
\hline
\end{tabular}

Table 6

Percentages of the Sub-Moves in the Corpus

\begin{tabular}{|c|c|c|c|c|c|c|c|c|c|c|}
\hline & 19 & $1 \mathrm{~b}$ & 1c & 1d & $3 \mathbf{a}$ & $3 \mathbf{b}$ & $3 c$ & $5 \mathbf{a}$ & $5 b$ & $5 c$ \\
\hline Iranians & $25 \%$ & $48 \%$ & $42 \%$ & $10 \%$ & $2 \%$ & $88 \%$ & $82 \%$ & $97 \%$ & $25 \%$ & $18 \%$ \\
\hline Natives & $20 \%$ & $80 \%$ & $45 \%$ & $27 \%$ & $0 \%$ & $58 \%$ & $60 \%$ & $98 \%$ & $18 \%$ & $13 \%$ \\
\hline Total & $23 \%$ & $64 \%$ & $43 \%$ & $18 \%$ & $1 \%$ & $73 \%$ & $71 \%$ & $98 \%$ & $22 \%$ & $16 \%$ \\
\hline
\end{tabular}

Figure 2. Frequencies of the Sub-Moves

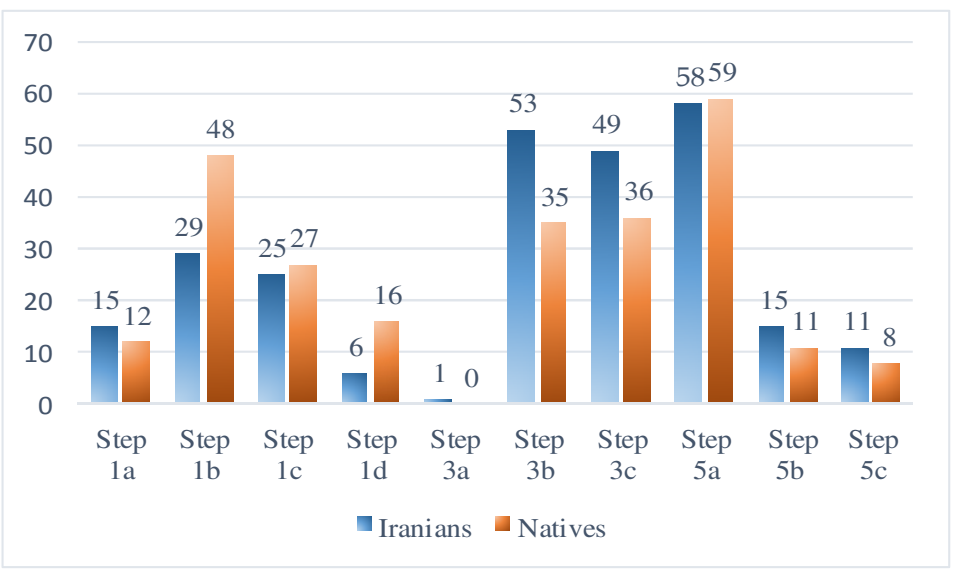




\subsection{The Results of Move Analysis}

In order to acquire information about the move structure in the ISI article abstracts in the field of agricultural engineering and the differences among Iranian and native scholars, some inferential and descriptive analyses were conducted. Based on the obtained results, it can be noted that there was no significant difference between Iranian and native writers in the field of agricultural engineering in using Move 2, Move 4, and Move 5 because the $p$ values were greater than .05. Almost all abstracts written either by Iranian or by native scholars contained these moves and they were considered obligatory moves by both Iranian and native scholars. Concerning Move 1, the difference was significant $(p=.02)$ and native writers used this move in their abstracts more than Iranian writers did. This move was regarded as obligatory by native scholars and optional by Iranian scholars $(65 \%$ Iranian abstracts and 85\% native abstracts). Regarding Move 3, there was also as significant difference $(p=.004)$ and Iranian writers used this move in their abstracts more than native writers did (93\% Iranian abstracts and $72 \%$ native abstracts).

Regarding sub-moves, significant differences were there only in Step 1b ( $p=.01)$, Step 1d $(p=.03)$, Step 3b $(p<.001)$, and Step 3c $(p=.016)$. Sub-Move $1 \mathrm{~b}$ existed in $48 \%$ of the abstracts written by Iranian scholars while $85 \%$ of the abstracts written by native scholars contained this sub-move. Therefore, this step was considered optional by Iranian writers and obligatory by native writers. Sub-Move 1d occurred in $10 \%$ of the abstracts written by Iranian writers and $27 \%$ of the abstracts written by native writers. Thus, this sub-move was regarded as optional by both Iranian and native scholars. Sub-Move $3 \mathrm{~b}$ existed in $88 \%$ of the abstracts written by Iranian scholars while $58 \%$ of the abstracts written by native scholars had this sub-move. Therefore, this sub-move was considered obligatory by Iranian writers and optional by native writers. Sub-Move 3c existed in $82 \%$ of the abstracts written by Iranian scholars while $60 \%$ of the abstracts written by native scholars had this sub-move. Consequently, this sub-move was considered obligatory by Iranian writers and optional by native writers.

The only sub-move that was regarded as obligatory by both Iranian and native scholars was Sub-Move 5a because only two abstracts written by Iranian scholars and one abstract written by native scholars did not have this step. The other sub-moves containing 1a, 1c, 3a, 5b, and 5c were considered optional by both groups of writers due to their very low occurrences in the abstracts and there were not any significant differences between Iranian and native writers in using these steps in their abstracts. The results of the tests and their analyses are illustrated in the following table.

\section{Table 7}

The Results of all Moves and Steps

\begin{tabular}{lccccccc}
\hline & \multicolumn{2}{c}{ Frequencies } & \multicolumn{3}{c}{ Percentages } & \multicolumn{2}{c}{ Chi-Squares Results } \\
\cline { 2 - 7 } & Iranians & Natives & Iranians & Natives & Total & $X^{2}$ & Asymp. Sig. \\
\hline Move 1 & 39 & 51 & 65 & 85 & 75 & 5.38 & .02 \\
Step 1a & 15 & 12 & 25 & 20 & 23 & .19 & .66 \\
Step 1b & 29 & 48 & 48 & 80 & 64 & 11.74 & .01 \\
Step 1c & 25 & 27 & 42 & 45 & 43 & .03 & .85 \\
Step 1d & 6 & 16 & 10 & 27 & 18 & 4.51 & .03 \\
Move 2 & 60 & 60 & 100 & 100 & 100 & & .004 \\
Move 3 & 56 & 43 & 93 & 72 & 83 & 8.31 & .000 \\
Step 3a & 1 & 0 & 2 & 0 & 1 & & .016 \\
Step 3b & 53 & 35 & 88 & 58 & 73 & 12.32 & 1.00 \\
Step 3c & 49 & 36 & 82 & 60 & 71 & 5.81 & .00 \\
Move 4 & 59 & 58 & 98 & 97 & 98 & & .00 \\
Move 5 & 59 & 59 & 98 & 98 & 98 & .00 & .62 \\
Step 5a & 58 & 59 & 97 & 98 & 98 & .44 & .00 \\
Step 5b & 15 & 11 & 25 & 18 & 22 & .42 & \\
Step 5c & 11 & 8 & 18 & 13 & 16 & 25 & \\
\hline
\end{tabular}




\subsection{Discussion}

The focus of the first research question was on figuring out the rhetorical moves that are used by Iranian scholars in the field of agricultural engineering for writing the abstract section of ISI articles. Findings revealed that all rhetorical moves existed in more than half of the abstracts written by Iranian writers in the corpus. These findings are in line about Move 2, Move 3, Move 4, and Move 5 with the results of the study that was done by Hashemi and Saboori (2013) in the field of mechanical engineering and not in agreement about Move 1. Based on the results of their study, more than half of the abstracts written by Iranian writers contained Move 3, Move 4, Move 5, while less than half of the abstracts contained Move 1. The results of the current study are also in line in relation to Move 2, Move 3, and Move 4 with the findings of the study that was done by Abarghooeinezhad and Simin (2015) in the field of electronic engineering and not in agreement about Move 1 and Move 5. They stated that more than half of the abstracts written by Iranian scholars in their study contained Move 2, Move 3, and Move 4, while less than half of them contained Move 1 and Move 5.

Regarding the sub-moves, more than half of the abstracts written by Iranian scholars contained Sub-Move 3b, Sub-Move 3c, and Sub-Move 5a, whereas less than half of them contained other sub-moves. Based on these results, it seems that the background of the study and identifying the gap in the abstracts are not very important to Iranian scholars and they tend to focus more on presenting the study, introducing the methodology and the procedure and equipment, results, and deducing conclusions from the study. It can also be understood that Iranian scholars are not very interested in presenting recommendations and evaluating their own research.

It is noteworthy to point out that, providing the background knowledge is not very important to Iranian writers because they probably believe that this part is not necessary and other parts of the abstracts that are directly related to their research are more important. On the other hand, they pay a lot of attention to providing Move 2, Move 3, and Move 5 since readers usually look for these kinds of information when they read an abstract and consequently an entire article. In addition, they pay heed to describe the process of doing their studies and the materials and equipment that they used for conducting them because readers can have a better understanding of the nature and the goals of the research if they are familiar enough with these points.

The second research question focused on determining the rhetorical moves that are used by native scholars in the field of agricultural engineering in the abstract section of ISI articles. The findings indicated that more than half of the abstracts written by native scholars in the corpus contained all rhetorical moves. These findings are in line with the results of the study that was done by Abarghooeinezhad and Simin (2015) in the field of electronic engineering about all moves except Move 5, because in their study less than half of the abstracts written by native scholars contained Move 5. The similar results are yielded in relation to the study that was conducted by San and Tan (2012) in the fields of computer and communication systems engineering. According to the results of their study, only the occurrence of Move 5 was less than $50 \%$ in research article abstracts. Therefore, it could be concluded that deducing the results from the study is very important in agricultural engineering in comparison with other areas of engineering.

Considering the sub-moves, more than half of the abstracts written by native scholars contained Sub-Move 1b, Sub-Move 3b, Sub-Move 3c, and Sub-Move 5a, while less than half of them contained other sub-moves. It reveals that unlike Iranian scholars, native scholars pay considerable attention to expressing the background of the study at the beginning of their research. Similar to Iranian scholars, it is very important to native scholars to present their research, describe the methodology and equipment of the study, explain the results, and deduce conclusions from their studies. It could be determined that native scholars do not pay significant attention to identifying the gap, presenting recommendations, and evaluating their studies.

It is believed that if a reader wants to understand a text about a specific subject, first they need to increase their background knowledge about that subject (Lent, 2012; Marzano, 2004). Unlike Iranian scholars, native scholars try to provide a proper background knowledge for their readers. They are also interested in providing 
A structural move analysis of the abstract section of ISI articles of Iranian and native scholars

the purpose, results, and conclusions of their studies in their abstracts since readers usually seek these data. On the other hand, native writers focus less on describing the methodology, equipment, and process of conducting since they believe either that these data are not very important to their readers or their readers are familiar enough with them.

The third research question focused on understanding the optional and obligatory moves and sub-moves in the abstracts written by Iranian and native scholars. As previously mentioned, the occurrence of a move or step in a set of abstracts must be at least $80 \%$ to be considered obligatory based on the hypothesis that was proposed by Santos (1996) and Pho (2008). Based on this premise, Move 2, Move 4, and Move 5 were considered obligatory by both groups of writers in the study. Move 1 was regarded as obligatory by native scholars and optional by Iranian scholars, whereas Move 3 was considered obligatory by Iranian researchers and optional by native researchers. These findings indicate that native scholars pay more attention to expressing the previous knowledge, while Iranian scholars pay more attention to describing the methodology of their studies.

It is obvious that unlike other fields of engineering, providing conclusions from the research is a very important part in agricultural engineering. It can be concluded that the readers of the articles in this field look for conclusions and recommendations when they want to read an abstract. In addition, like most fields of study, the purpose and results are regarded as obligatory in abstracts (Behnam \& Golpour, 2014; Hashemi \& Saboori, 2013; San \& Tan, 2012; Wei, Liu, \& Liu, 2015) providing these two moves are also very important and considered obligatory in agricultural engineering.

However, these findings are not in line with the results of some previous studies in some aspects. For instance, San and Tan (2012) claimed that in the field of computer engineering only Move 1 and Move two are considered obligatory and other moves are regarded as optional. These findings are not in line either with the results of the study that was performed by Maswana et al. (2015). They stated that only Move 2 and Move 4 are considered obligatory moves in most engineering disciplines since these two moves have the frequency of greater than $80 \%$. They maintained that Move 5 is considered optional in all abstracts that were analyzed by them since the occurrence of this move was less than $35 \%$ in the abstracts in the disciplines of structural, environmental, chemical, computer, and electrical engineering.

Considering the sub-moves, only Sub-Move 5a was considered obligatory by both Iranian and native writers. Step $1 \mathrm{~b}$ was considered obligatory by native scholars, while Step $3 \mathrm{~b}$ and Step $3 \mathrm{c}$ were regarded as obligatory by Iranian scholars and optional by native scholars. It can be concluded that Iranian writers have a tendency to describe their methodology in detail, but native writers prefer to introduce their methodology and give their previous knowledge about the study to their readers to make them become more familiar with it.

The focus of the fourth research question was to figure out if there was a significant difference between Iranian and native researchers in using the moves and sub-moves, therefore some inferential statistics were performed to find suitable answers to this question. According to the results, there were significant differences about Move 1 and Move 3, while there were not any significant differences about other moves. Iranian scholars were more interested in using Move 3 whereas native scholars were more interested in using Move 1 in their abstracts. These findings are not in line with the results of the study that was done by Abarghooeinezhad and Simin (2015). They maintained that there was no significant difference between Iranian and native scholars in the field of electronic engineering in using the rhetorical moves in their abstracts.

Regarding the sub-moves, significant differences were there only in Step 1b, Step 3b, and Step 3c. Native scholars used Step 1b significantly more than Iranian scholars in their abstracts, while the use of Step 3b and Step $3 c$ by Iranian writers were significantly higher in comparison with native writers.

\section{Conclusion}

Based on the above-mentioned discussion some concluding remarks can be drawn. Although there were 
some differences between Iranian and native scholars in the field of agricultural engineering in using the rhetorical moves and sub-move in their abstracts, Iranian writers were familiar enough with the moves and their abstracts and their abstracts were organized and the move pattern was used properly in most of their abstracts.

The other point is about the model that was used in the study. Some researchers stated that a five-move model is not very suitable for analyzing abstracts in engineering disciplines because the majority of abstracts in these fields do not contain five moves and Move 1 and Move 5 are not very common in their abstracts (Abarghooeinezhad \& Simin, 2015; Hashemi \& Saboori, 2013; Maswana et al., 2015; San \& Tan, 2012). However, this vantage point is not accurate in agricultural engineering since the majority of the abstracts in the present study written by either Iranian or native scholars contained all five moves, therefore it can be concluded that Hyland's (2000) model is suitable for analyzing the abstracts in the field of agricultural engineering.

It can be noted that the most important moves and steps for writing abstracts in the field of agricultural engineering are making topic generalizations, stating the purpose, describing the instruments or equipment, describing the procedure and conditions, describing the results of the study, and deducing conclusions from the results. According to the aforementioned viewpoint, a model is suggested for writing abstracts in the field of agricultural engineering.

\section{Table 8}

Suggested Move Pattern for Writing Abstracts in the field of Agricultural Engineering

The Suggested Move Pattern

Move 1: Introduction

Sub-Move 1: Making Topic Generalizations

Move 2: Purpose

Sub-Move 1: Stating the purpose directly

Move 3: Method

Sub-Move 1: Describing the Instruments or Equipment

Sub-Move 2: Describing the Procedure and Conditions

Move 4: Product

Sub-Move 1: Describing the main features or properties of the solution or product

Move 5: Conclusion

Sub-Move 1: Deducing Conclusions from Results

Ultimately, the following conclusions were drawn as the results of the current study. The rhetorical moves of Introduction, Purpose, Method, Product, and Conclusion are used by Iranian scholars in the field of agricultural engineering in the abstract section of ISI articles. The rhetorical moves of Introduction, Purpose, Method, Product, and Conclusion are used by native scholars in the field of agricultural engineering in the abstract section of ISI articles. Move 2, Move 3, Move 4, and Move 5 are considered obligatory and Move 1 is considered optional by Iranian scholars, while Move 1, Move 2, Move 4, and Move 5 are considered obligatory and Move 3 is considered optional by native scholars. There are significant differences between Iranian and native scholars in Move 1, Move 3, Sub-Move 1b, Sub-Move 1d, Sub-Move 3b, and Sub-Move 3c, whereas there are not any significant differences for other moves and steps between Iranian and native scholars.

\section{References}

Abarghooeinezhad, M., \& Simin, S. (2015). A structural move analysis of abstract in electronic engineering articles. International Journal of Research Studies in Language Learning, 4(4), 69-80. https://doi.org/10.5861/ijrsll.2015.1073

American Psychological Association. (2001). Publication manual of the American psychological association. Washington DC: American Psychological Association.

Anthony, L. (2003). AntMover (Version 1.0.0). Tokyo, Japan: Waseda University. Retrieved from http://www.laurenceanthony.net/

Behnam, B., \& Golpour, F. (2014). A genre analysis of English and Iranian research articles abstracts in applied 
A structural move analysis of the abstract section of ISI articles of Iranian and native scholars

linguistics and mathematics. International Journal of Applied Linguistics and English Literature, 3(5), 173-179.

Bhatia, V. K. (2001). Analyzing genre: Some conceptual issues. In M. Hewings (Ed.), Academic writing in context (1st ed., pp. 79-92). London, England: Bloomsbury Publishing.

Bhatia, V. K. (2004). Worlds of written discourse: A genre-based view. London, England: A\&C Black.

Bhatia, V. K. (2014). Analyzing genre: Language use in professional settings. New York, NY: Longman.

Bhatia, V. K. (2015). Critical genre analysis: Theoretical preliminaries. HERMES-Journal of Language and Communication in Business, 27(54), 9-20. https://doi.org/10.7146/hjlcb.v27i54.22944

Blake, G., \& Bly, R. W. (1993). The elements of technical writing. London, England: Macmillan.

Ding, H. (2007). Genre analysis of personal statements: Analysis of moves in application essays to medical and dental schools. English for Specific Purposes, 26(3), 368-392. https://doi.org/10.1016/j.esp.2006.09.004

Dos Santos, M. B. (1996). The textual organization of research paper abstracts in applied linguistics. Text-Interdisciplinary Journal for the Study of Discourse, 16(4), 481-500. https://doi.org/10.1515/text.1.1996.16.4.481

Hashemi, M. R., \& Saboori, F. (2013). A cross-disciplinary move analysis of research article abstracts. International Journal of Language Learning and Applied Linguistics World, 4(4), 483-496.

Hyland, K. (2000). Disciplinary discources. Social interactions in Academic writing. Harlow, England: Pearson Education Limited.

Hyland, K. (2008). Genre and academic writing in the disciplines. Language Teaching, 41(4), 543-562. https://doi.org/10.1017/S0261444808005235

Lent, R. C. (2012). Overcoming textbook fatigue: 21 st century tools to revitalize teaching and learning. Alexandria, VA: ACSD.

Marzano, R. J. (2004). Building background knowledge for academic achievement: Research on what works in schools. Alexandria, VA: ASCD.

Maswana, S., Kanamaru, T., \& Tajino, A. (2015). Move analysis of research articles across five engineering fields: What they share and what they do not. Ampersand, 2, 1-11. https://doi.org/10.1016/j.amper.2014.12.002

Nasseri, D., \& Nematollahi, B. (2014). A contrastive genre analysis of abstract of Master of Arts (Ma) theses in applied linguistics written by native and non-native speakers of English with respects to moves and move markers. Indian Journal of Science Research, 7(1), 1353-1366.

Pho, P. D. (2008). Research article abstracts in applied linguistics and educational technology: A study of linguistic realizations of rhetorical structure and authorial stance. Discourse Studies, 10(2), 231-250. https://doi.org/10.1177/1461445607087010

Richards, J. C., \& Schmidt, R. (2010). Longman dictionary of language teaching and applied linguistics (4th ed.). London, England: Routledge.

San, L. Y., \& Tan, H. (2012). A comparative study of the rhetorical moves in abstracts of published research articles and students' term papers in the field of computer and communication systems engineering. International Journal of Applied Linguistics and English Literature, 1(7), 40-50. https://doi.org/10.7575/ijalel.v.1n.7p.40

Suntara, W., \& Usaha, S. (2013). Research article abstracts in two related disciplines: Rhetorical variation between linguistics and applied linguistics. English Language Teaching, 6(2), 84-99. https://doi.org/10.5539/elt.v6n2p84

Swales, J. M. (1981). Aspects of article introductions. Birmingham, England: Language Studies Unit, University of Aston.

Swales, J. M. (1990). Genre analysis: English in academic and research settings. Cambridge, England: Cambridge University Press.

Swales, J. M. (2004). Research Genres: Explorations and applications. Cambridge, England: Cambridge University Press. https://doi.org/10.1017/CBO9781139524827

Van Bonn, S., \& Swales, J. M. (2007). English and French journal abstracts in the language sciences: Three 
Tavakoli Gheinani, M., \& Tabatabaei, O.

exploratory studies. Journal of English for Academic Purposes, 6(2), 93-108. https://doi.org/10.1016/j.jeap.2007.04.001

Viera, A. J., \& Garrett, J. M. (2005). Understanding interobserver agreement: the kappa statistic. Fam Med, 37(5), 360-363.

Wang, Y. L. (2015). Rhetorical variation of RA abstracts between experts and Chinese undergraduates. In International Conference on Social Science, Education Management and Sports Education (pp. 842-845). Beijing, China: Atlantis Press. https://doi.org/10.2991/ssemse-15.2015.216

Wei, M., Liu, Y., \& Liu, J. (2015). A comparative analysis of the generic structure of RA English abstracts in Chinese-medium and English-medium linguistics journals. English Language and Literature Studies, 5(4), 98-107. https://doi.org/10.5539/ells.v5n4p98 